\title{
Das Unsagbare
}

\section{Erhard Taverna}

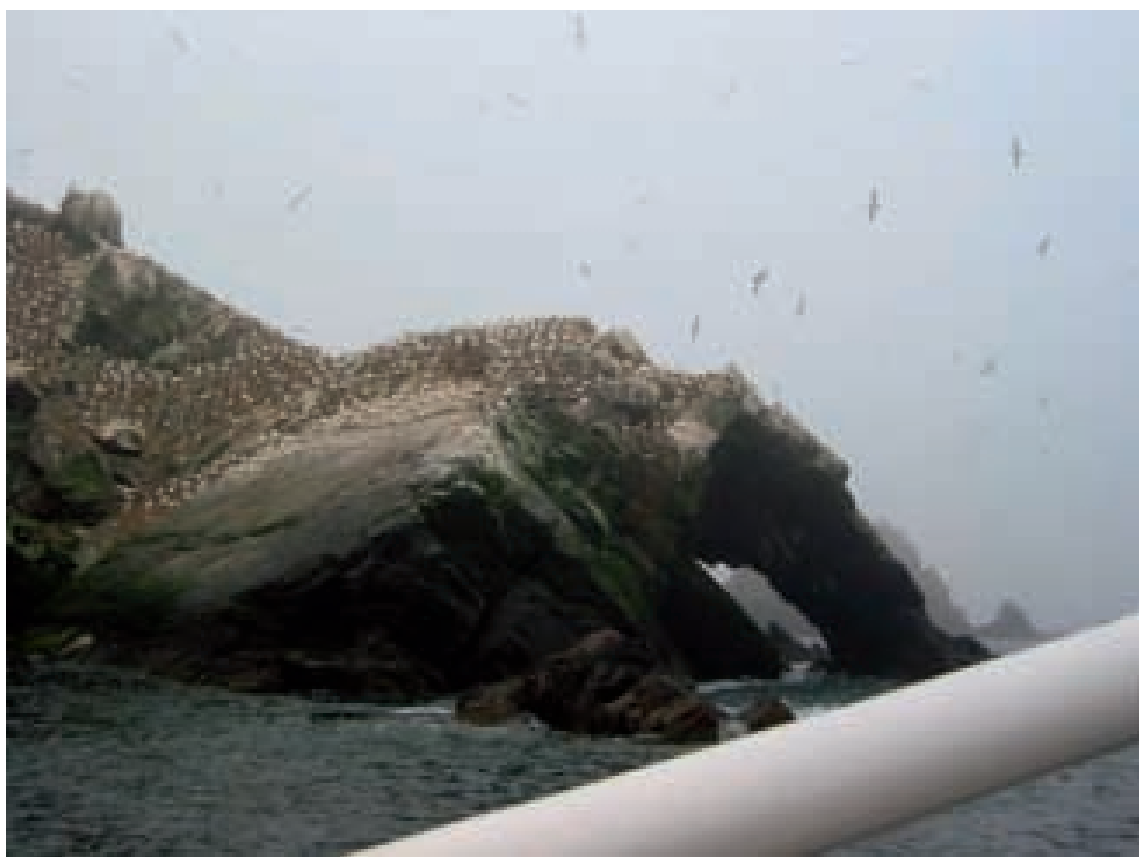

Wie kann ein Maler das Nichts darstellen oder ein Geheimnis? Er verhüllt es mit einem Schleier, mit weissen, ineinandergeflochtenen Bändeln. Das Nichtdarstellbare, nicht einmal Denkbare hat eine menschliche Gestalt, wird Gott geheissen und hat soeben Adam geschaffen, eine liegende Figur mit einem Namen wie ein Preisschild. Wahrscheinlich ist sie schon belebt, denn sie hat die Augen offen. Durch den Schleier des Nichts stecken vier Engel ihre Köpfe, sie sind die Zeugen. Eva wird erst im nächsten Bild erschaffen, aus der Seite Adams, da ist der Schleier schon gelüftet.

Die Stille ist voller Geräusche, aber ohne Lärm, sie schärft die Sinne. Hören, riechen, sehen vor allem, aber auch fühlen, schmecken und empfinden. Alles wirkt unvermittelt, weil es einfach ist, weil es ohne Zutun existiert, ohne menschliches Bemühen oder zumindest fast ohne. Denn Garten, Hecken und Felder sind Spuren der Arbeit, auch wenn die Akteure selten sichtbar sind. Das Haus aus Granitsteinen liegt an einer kaum befahrenen Strasse, die Nachbarin lässt sich nie blicken, die Besitzer sind ausgezogen und die Nachfolger erst in einer Woche zu erwarten. Fast die ganze Südseite ist von einem Rosenspalier bedeckt. Sie wachsen gelb, weiss

und rot beidseits des Gebäudes, alte Sorten, kräftig gefüllte Blütenköpfe, die immerzu duften. Jede verströmt ihr Parfum in Nuancen, taubenetzt am kühlen Morgen, hummelnbekrabbelt in der Mittagshitze, schwer am Abend, wieder anders bei Wind und Regen und zuletzt noch aus den lockeren Haufen Blütenblättern, die auf dem Kiesweg liegen. In den Geruch mischt sich das Geissblatt und besonders in den ersten Wochen der bittersüsse Holunder. Die Zeit mischt mit, komponiert neue Partituren, je nach Wachstum und Reife. Ist der Duft an mir verschwendet, weil ich sie alle nicht bestäube, weder tags noch nachts anfliege, sie höchstens nach Farbe und Aussehen sortiert in eine Vase stecke, wo sie bald verwelken? Vom Meer kommen eine Prise Salz und Seegras, von den Äckern Heu- und Kompostgeruch. An den Wegböschungen wachsen Brennesseln, Schafgarben, Nelken und Eisenhut, langsam ändert das Muster unzähliger Kräuter und Blumen, mir bekannter und unbekannter. Die da einfach sind, vielfach ineinander verwoben, wie der Schleier des Nichts an der gewölbten Holzdecke von St. Gonery. Und immer der unsichtbare Kuckuck und die vielen Tauben. Sie gurren nicht, das tun die Frösche am Trieux. Für mich klingen sie wie kauzige Mollakkorde in variationsreichen Wiederholungen, aufgescheucht aus Kornfeldern, aus dem Schatten der Baumvolieren, vom Dachfirst, von überall. Eine Etage höher kurven Schwalben wie Pfeile auf der Mückenjagd, Spatzen tschilpen, auf biegsamen Halmen wippen kleinste Vögel, Zaunkönige? All die Namen, die einordnen und etikettieren. Aha, denke ich, ein Sowiesodings, und schaue gar nicht mehr richtig hin, bilde mir ein, der Name sei das Ding an sich. Dabei blickt kurz ein Schnabel durch den Schleier, ein Reptilienauge, ein Gefieder wie von einem Erzengel. Ihre Augen erspähen die Nordküste, die Winterstürme und Merlins Schlehdornverlies. Sie sehen auf ihre Art, müssen mir nichts erklären; nur ich muss mich dauernd anstrengen. Adam und Eva sind von Gabriel weggewiesen, flammend verwehrt er die Rückkehr. Sie sind mit einem seltsamen Kostüm bekleidet, mit einem Netzkleid aus Weinblättern, ähnlich einem militärischen Tarnanzug. Ein Blätterkleid, wenn auch ein dichteres, hat der Maler am Anfang der Schöpfung den Cherubinen verpasst. Zufall oder Absicht? Vielleicht ist es das 
kreatürliche Sein, Mann und Frau nach dem Auszug, sich selbst überlassen. Die bereitgestellte Spindel ist noch ungebraucht, kein Text ist geschrieben. Beides wird ihre Blösse verhüllen.

Hören und riechen, dazu die Wärme der Sonnenstrahlen, ein Luftzug auf der Haut, ihr Geschmack, wenn die Salzkristalle vom Strand daran kleben. Prickelnder Cidre auf der Zunge, Fisch und Olivenöl, Thymian und Rosmarin. Flüchtige Zirruswolken, ein kupferner Abendhimmel, Nebel über dem grauen Wasser, schwarze Felstürme, Sonnenkringel auf dem
Waldboden des Litorals. Wenn das Gedankenkarussell stillsteht, geht meine Ruhe in eine grössere über. Glück mischt sich mit der Furcht, nicht mitgemeint zu sein. Ein Fremdling im Reich der Sinne, vogel- und blumenhaft und doch nicht zugehörig, ein Gast, der zuviel Platz beansprucht, sich wie ein Räuber benimmt. Einer, der sein Schicksal an die Decke malt und nachts Gespenster sieht. Bis morgens der Duft vom Geissblatt den Herzschlag besänftigt und das Auf und $\mathrm{Ab}$ der Gezeiten den Atem beruhigt.

\title{
Kinder wagen
}

\author{
B. Gurtner
}

Korrespondenz:

Dr. med. Bernhard Gurtner Eggstrasse 76 CH-8620 Wetzikon
So faule und unbeholfene Väter waren wir damals nicht, obwohl wir zugeben müssen, dass wir im Schoppenrichten und Windelnwechseln nicht über die professionelle Gewandtheit verfügten, welche moderne junge Frauen ganz selbstverständlich von ihren Lebenspartnern erwarten. Wie brauchbar unsere Generation dennoch ist, zeigt sich jeden Werktag auf zahlreichen Spazierwegen und innerstädtischen Trottoirs, wo bärtige oder glatzköpfige Grossväter ihre Enkel spazierenfahren, deren beide Eltern berufstätig sind. Dass Grossmütter diese Bébébetreuung bestens erledigen, steht ausser Frage, sie brauchen nur alte Reflexe zu wecken. Für Grossväter, die in sehr männlichen Berufen gearbeitet haben, kommt der Auftrag aber manchmal etwas überraschend, sie würden lieber eine blökende Schafherde hüten, als den eigenen schreienden Enkel zu «gaumen». Und so schieben sie den Kinderwagen mit gespielter Lässigkeit oder ängstlicher Umsicht über die gleichen Rundstrecken, auf denen ihre Kollegen mit den Hunden Gassi gehen. Immerhin kommen sie so an die frische Luft, sofern sie nicht mit der einen Hand stossen und in der anderen ein glühendes Rauchzeug halten.

Als unsere Eltern zur Welt kamen, war es unüblich, ja fast revolutionär, wenn sich ein stolzer Vater dazu hergab, seinen Sprössling selbst zu schieben. Damals gab es noch die weichgefederten, wunderschönen hochrädrigen Kinderwagen, deren blankgeputzte Speichen im Son- nenlicht aufblitzten. Das straffgewickelte Kind lag in einem aus Binsen geflochtenen luftigen Korb unter einem Baldachin, der rundum mit allerlei Bändern und Rüschen verziert war. Diese edlen Gefährte waren so damenhaft, dass sie kein Schnauzträger anzufassen wagte.

In den Krisenjahren vor dem Zweiten Weltkrieg schrumpften die eleganten Kinderwagenmodelle zu kleinrädrigen, unförmigen Kisten, die kaum mehr gefedert waren, weil nun ja überall Asphalt lag. Wurden die Kinder grösser, dienten die fahrbaren Behälter in vielen Familien noch lange als Transportmittel für Brennholz, alte Zeitungen oder gesammeltes Fallobst. Manchmal wurden sie auch von den Buben für Seifenkistenrennen umgebaut. Die schwachen Blechfelgen und schmalen Vollgummireifen waren dieser Zweckentfremdung und höheren Belastung nicht gewachsen; es gehörte zum Strassenbild der Nachkriegsjahre, dass Pannenhilfe für verunglückte Wisa-Gloria-Wagen geleistet werden musste.

Für unsere eigenen Nachkommen gab es dann bereits etwas bessere Ausführungen. Es ging aber recht lange, bis sich die Industrie darauf einstellte, dass Kinderwagen in kleine Autos eingeladen werden mussten und deshalb leicht demontierbar sein sollten. Zuvor hatten wir Väter das sonntägliche Vergnügen, Stossstangen oder Verdecke loszuschrauben und alle vier festmontierten Räder abzunehmen, deren «Karrensalbe» an den Händen und Hosen nachhaltige 
Spuren hinterliess, die sogar der Ochsengallenseife widerstanden. Ein Geheimtip war es deshalb, die Quietschgeräusche der Räder nicht mit gewöhnlichem Schmierfett, sondern mit derselben reinen Vaseline zu beseitigen, die auch für die Pflege wunder Säuglingspopos verwendet wurde.

Der französische Döö-Schwoo war etwas familienfreundlicher als der spiessbürgerliche deutsche VW Käfer, der spätestens nach der Geburt des zweiten Kindes durch einen Kombi mit grosszügigerem Laderaum ersetzt werden musste, falls man die Kleinen nicht in die platzsparenden «Sportwagen» zwängen wollte, die nun allmählich aufkamen. Die Konstruktionen waren weder sporttauglich noch genial durchdacht. Manche gestresste Mutter bemühte sich auf dem Parkplatz vergeblich, das verklemmte Gestänge einhändig in die richtige Lage zu schütteln, während der andere Arm einen plärrenden Gof und den Regenschirm festzuhalten versuchte. Da klappte die Frau oft noch vor dem faltbaren Kinderwagen zusammen.

Ja, und heute? Den Grossvätern bleibt nur sprachloses Erstaunen, wenn sie sehen, was da an perfektionierten Kindertransportmitteln aus den geräumigen Offroadern ausgeladen wird. Nicht nur die Familienautos sind geländegängig, auch die Kinderwagen sind so robust und zudem leicht konstruiert, dass sie der übergewichtige
Papa beim Joggen oder das sportliche Mami beim Inlineskating problemlos vor sich herstossen können. 5-Punkte-Festhaltegurt, Fangschlaufe und Überrollbügel sind TÜV-geprüft und verhindern das Schlimmste, falls es zu Kollisionen mit anderen rasenden Säuglingen kommen sollte. Bei Regen kann ein Verdeck mit Panoramafenster übergestreift werden. Eine Handbremse dosiert die Geschwindigkeit auf abfälligen Strecken. Nur blinkende Richtungsanzeiger und Scheinwerfer fehlen noch. Flaschen und Picknickkörbe können in praktische Halterungen eingesteckt werden, auch ein Stehbrett für das mitfahrende ältere Geschwister lässt sich unten anbringen, doch warnen Psychologen davor, die Kinder so früh schon als Trittbrettfahrer vor jeder Eigenleistung zu verschonen.

Die dreirädrigen Vehikel sind leichter zu steuern als die Einkaufswagen in den Supermärkten, weshalb sie Grossväter auch ohne Fahrschule beherrschen dürften. Es wird ihnen aber dringlich empfohlen, die vielfach regulierbaren Liege- und Sitzpositionen, die Höhen- und Rastereinstellungen, das aufsteckbare und abnehmbare Zubehör, die Verschlüsse und Sicherungsstifte und alle anderen Weiss-der-GuggerRaffinessen genau zu studieren, bevor sie es wagen, innerorts oder querfeldein mit lebendiger Fracht loszuziehen. Schieben, nicht ziehen! 